\title{
Neuroprognostication of Cardiac Arrest Patients: Outcomes of Importance
}

\author{
Tobias Cronberg, MD, $\mathrm{PhD}^{1}$ \\ 1 Department of Clinical Sciences Lund, Neurology, Lund University, \\ Skane University Hospital, Lund, Sweden \\ Semin Respir Crit Care Med 2017;38:775-784.
}

\begin{abstract}
Address for correspondence Tobias Cronberg, MD, PhD, Division of Department of Neurology, Skane University Hospital, 22185 Lund, Sweden (e-mail: Tobias.Cronberg@skane.se).
\end{abstract}

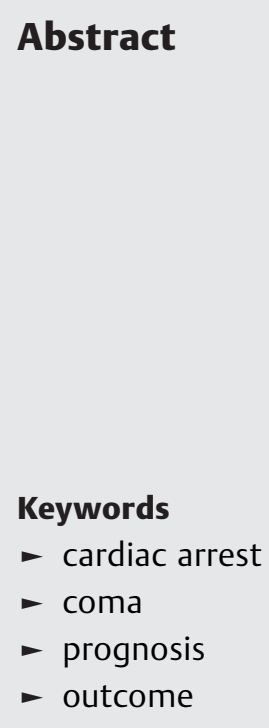

During the last two decades, survival rates after cardiac arrest have increased while the fraction of patients surviving with a severe neurological disability or vegetative state has decreased in many countries. While improved survival is due to improvements in the whole "chain of survival," improved methods for prognostication of neurological outcome may be of major importance for the lower disability rates. Patients who are resuscitated and treated in intensive care will die mainly from the withdrawal of lifesustaining (WLST) therapy due to presumed poor chances of meaningful neurological recovery. To ensure high-quality decision-making and to reduce the risk of premature withdrawal of care, implementation of local protocols is crucial and should be guided by international recommendations. Despite rigorous neurological prognostication, cognitive impairment and related psychological distress and reduced participation in society will still be relevant concerns for cardiac arrest survivors. The commonly used outcome measures are not designed to provide information on these domains. Followup of the cardiac arrest survivor needs to consider the cardiovascular burden as an important factor to prevent cognitive difficulties and future decline.
A patient who remains unresponsive days after a cardiac arrest presents the intensive care team with a considerable challenge. If you are in charge of this patient, you may consider whether unconsciousness is due to a brain injury and whether this injury is compatible with an eventual return to a meaningful life if intensive care is continued. If you decide to continue care, you may consider whether there are measures to optimize neurological recovery or at least prevent further injuries from developing. If you and your team decide to withdraw intensive care due to a presumed poor prognosis, the outcome of the patient will almost certainly be poor due to the "self-fulfilling prophecy," a prediction that directly or indirectly causes itself to become true, making such decisions particularly grave. To inform your decisions, you, therefore, need precise tools to assess the extent of injury inflicted during the brief period of circulatory standstill, but you also need a sound concept of the implications of the expected outcome, good or poor, in terms of quality of life and participation in society. Also, you need to be prepared to tackle the ethical aspects, within your team and together with the patient's relatives. ${ }^{1}$ A well-informed decision on withdrawal of life-sustaining therapy (WLST) may be of great benefit for the relatives, whereas a poorly informed and/or poorly communicated decision and WLST may leave the relatives traumatized, pondering the reasons for withdrawal and alternative outcomes for a long time. In this narrative review, the complex relationship between cardiac arrest-induced brain injury, WLST, prognostication, and long-term outcomes will be explored. The aim is to put these challenging decisions into a wider perspective. The majority of data regard out-of-hospital cardiac arrest (OHCA), but the general principles can also be applied to patients with cardiac arrest in the hospital setting.

\section{Survival after Cardiac Arrest}

Cardiovascular disorders are the most common cause of death worldwide, ${ }^{2}$ and 75 to $80 \%$ of all cardiac arrests
Issue Theme Advancements in Neurocritical Care and Emergency Neurology; Guest Editors: David Y. Hwang, MD, FNCS, and David M. Greer, MD, MA, FCCM, FAHA, FNCS, FAAN, FANA
Copyright $\odot 2017$ by Thieme Medical Publishers, Inc., 333 Seventh Avenue, New York, NY 10001, USA.

Tel: +1(212) 584-4662.
DOI https://doi.org/ $10.1055 / \mathrm{s}-0037-1607988$. ISSN 1069-3424. 
occurring outside of the hospital have a primary cardiac cause, ischemic heart disease being most common. ${ }^{3}$ Not surprisingly, sudden OHCA is a common occurrence, with an estimated global incidence of 62 per 100,000 personyears. ${ }^{2}$ During the last two decades, improved survival rates from OHCA to approximately $10 \%$ have been reported by national registries in Europe and the United States. ${ }^{4,5}$ This is likely the result of improvements throughout the "chain of survival," 6 most importantly increased bystander cardiopulmonary resuscitation rates. ${ }^{7}$ Unfortunately, most cardiac arrests occur in the home and without a witness, limiting the achievable rates of bystander resuscitation and survival.

\section{Death after Successful Resuscitation}

Most patients who have a return of spontaneous circulation after resuscitation will be unconscious on arrival to the hospital, ${ }^{8}$ artificially ventilated, and subsequently treated at an intensive care unit (ICU) with targeted temperature management, sedation, and paralytics according to present international guidelines. ${ }^{6,9,10}$ Despite improvements in intensive care and more active cardiac reperfusion strategies, ${ }^{11}$ less than half of ICU-admitted cardiac arrest patients will survive to hospital discharge.

The cause of death among ICU-treated cardiac arrest victims has been documented in several, mainly European, studies. The brain is the organ that is most sensitive to a circulatory standstill due to its high metabolic rate and very limited energy supplies. Hence, brain injury is the most common cause of death for resuscitated patients. ${ }^{12-15}$ In the first 1 to 2 days after the cardiac arrest, patients die mainly due to cardiac or multiorgan failure. During the remaining period in the hospital, death will usually follow an assessment of the neurological prognosis, and thereafter WLST based on the presumption of a severe brain injury and poor chances for neurological recovery. ${ }^{12,13}$

\section{Hypoxic-Ischemic Brain Injury}

Upon cessation of cerebral circulation due to a cardiac arrest, energy depletion will lead to unconsciousness and cessation of cortical electric activity on the electrocardiogram (EEG) within seconds. ${ }^{16}$ Further energy depletion will lead to anoxic depolarization with loss of membrane potentials, the release of excitatory glutamate, loss of ion gradients, and the influx of water and calcium ions, triggering further intracellular pathological processes. ${ }^{17}$ While the brain stem neurons are more resistant to injury from circulatory arrest, particularly vulnerable neurons are found in the hippocampus, cerebellum, and neocortex. ${ }^{18}$ Therefore, patients may survive in a minimally conscious state or vegetative state with very pronounced cortical injuries but a functioning brain stem, enabling weaning from the ventilator and survival if nutrition is provided. This differential vulnerability to hypoxic-ischemic challenge also explains why brain stem functions, such as ocular reflexes, usually return hours to days before higher cortical functions, such as consciousness in comatose patients after cardiac arrest.

\section{Intensive Care after Cardiac Arrest}

It is very difficult to assess with a high level of certainty the prognosis for recovery during the first hours immediately after the return of spontaneous circulation. Since most patients are unconscious at this time point, a general practice is to initiate intensive care assuming a possible good outcome, and then evaluate the extent of brain injury at a later time point. The intensive care bundle after cardiac arrest includes an assessment of the cardiac situation, often including coronary angiography and stenting of culprit lesions. ${ }^{11}$ To minimize the further development of brain injury, whole body temperature is usually controlled by temperature control devices for the next 24 hours, with a slow rewarming to normothermia thereafter. ${ }^{19}$ A reduction of the whole body temperature is, in fact, the only neuroprotective strategy that has translated from experimental studies to clinical use. The two pivotal studies presented in the New England Journal of Medicine in 2002 showed a significant reduction in mortality and neurological disability by targeting a temperature of 32 to $34^{\circ} \mathrm{C}$ for 12 to 24 hours, ${ }^{20,21}$ and led to a rapid implementation of temperature management in intensive care. The substantially larger targeted temperature management (TTM) trial, however, showed no benefit from targeting 33 versus $36^{\circ} \mathrm{C}$ on mortality, ${ }^{22}$ neurological functions, quality of life, ${ }^{23}$ or release of the biomarker neuron-specific enolase (NSE) in the serum. ${ }^{24}$ In a large substudy, the more detailed cognitive function was also found to be similar between the two intervention groups. ${ }^{25}$ Consequently, current guidelines recommend maintaining a constant temperature between 32 and $36^{\circ} \mathrm{C}$ for 24 hours for adults with cardiac arrest. ${ }^{9}$ Recently, Kirkegaard et al reported that 48 hours of cooling provided no extra benefit compared with 24 hours, although this study may have been underpowered to answer the question. ${ }^{26}$ Fever is associated with worse outcome after cardiac arrest. ${ }^{27}$ Lacking evidence from randomized trials, it is recommended to treat fever arising during the first days after temperature management by either antipyretic agents or temperature control devices. ${ }^{6,9}$

\section{Awakening after Cardiac Arrest}

During temperature management, the patient is sedated, artificially ventilated, and often treated with neuromuscular blocking agents to prevent shivering. Therefore, a pharmacologically induced coma is added to the decrease in consciousness caused by a possible brain injury. Sedative and analgesic drugs given during the first days will continue to affect the patient for a substantially longer period then what the ICU staff commonly expects from experience in other patients. Among the possible reasons are the concomitant brain injury, a slower metabolism due to hypothermia and also renal and hepatic injury which may be substantial.

For the small group of patients who awaken rapidly after resuscitation, significant brain injury is unlikely. Among patients who are treated at the ICU, a rapid recovery of motor response to painful stimulation after sedation is 
stopped, which is a strong indicator of a subsequent good outcome. A motor response better than extensor on the first day after sedation is stopped and a Glasgow Coma Scale score $>6$ on the following days is a reasonably robust predictor of a good neurological outcome. ${ }^{28}$ For patients who remain unresponsive, the prognosis for recovery becomes gradually worse with time, ${ }^{29}$ but it is important to keep in mind that delayed awakening is not uncommon and that the outcome is usually good also in patients with a delayed awakening. ${ }^{30}$

\section{Clinical and Electrographic Seizures}

Clinical convulsions and seizure patterns on EEG are common and occur in approximately $30 \%$ of all ICU-treated cardiac arrest victims. ${ }^{31,32}$ The vast majority consist of myoclonus, but approximately one-third of patients with clinical convulsions have tonic-clonic seizures, often in combination with myoclonus. ${ }^{32}$ Myoclonus is often relatively easily suppressed by sedative agents, and propofol may be particularly effective in this respect. ${ }^{33}$ Antiepileptic agents, such as valproate and levetiracetam are often also used. ${ }^{34}$ They are well tolerated and the serum levels easily monitored. Myoclonus is a sign of a severe brain injury, ${ }^{35}$ in particular if it is generalized and continuous $>30$ minutes, a condition termed "status myoclonus." If this occurs during the first 2 days after the arrest, the outcome is almost invariably poor $^{32}$ although exceptions are reported. ${ }^{36,37}$ Using continuous video EEG monitoring, Elmer et al recently showed that the combination of early posthypoxic myoclonus with a burst-suppression pattern on the EEG is highly malignant with no survivors $(n=48)$, whereas a combination with a continuous background EEG with high-amplitude polyspikes in lockstep with the myoclonic jerks was more benign, with $50 \%$ of patients having a favorable outcome $(n=8) .{ }^{38}$ Furthermore, all survivors with the latter combination later developed Lance Adams syndrome of actioninduced myoclonus. $^{39}$

Continuous EEG is recommended as a noninvasive instrument to monitor the recovery of a normal continuous EEG background or the development of pathological patterns. ${ }^{9,40}$ Electrographic status epilepticus (ESE) develops in approximately $30 \%$ of postanoxic patients if liberal EEG-based definitions are used. ${ }^{41-43}$ Most patients with ESE have clinical convulsions of some sort during brief or prolonged periods, but the ESE may also continue for days and sometimes weeks in a comatose patient without any external seizure manifestations. ESE typically develops during the first 1 to 2 days postarrest, either from a continuous background or from a suppression-burst pattern. ${ }^{41-43}$ Spiking frequency is usually highest during the first hours and gradually decrease over the following days. ${ }^{44}$ Also, with aggressive therapy including high doses of sedative agents and two or more antiepileptic drugs, postanoxic ESE tends to reappear as sedation is weaned. ${ }^{45}$ ESE developing from a high-voltage burst-suppression pattern does not seem to be compatible with survival, and these patients can be expected to have also other signs of a very pronounced brain injury. ${ }^{41,42,46}$ Among the group of patients who develop ESE from a continuous background, some 20 to $25 \%$ may survive and ultimately have a good outcome, usually after a prolonged recovery period over weeks. Despite being recommended in guidelines, active treatment of postanoxic ESE is not based on evidence, and a randomized clinical trial (TELSTAR) is ongoing. ${ }^{47}$

\section{Timing of Neurological Prognostication}

Since brain injury is the major determinant of survival and functional outcome after cardiac arrest, the assessment of such injury and the related prognosis for recovery of neurological functions are inherent parts of the critical care of cardiac arrest victims. Many reviews on this topic are available, ${ }^{48,49}$ but the author's advice is to use the most modern official guidelines ${ }^{6,9}$ to develop a local protocol, taking into account the available methods which may differ substantially between hospitals.

The gathering of prognostic information should start early and be performed continuously, ${ }^{50}$ as all methods have their defined time windows. Most authors recommend postponing decisions on level of care at least 72 hours after cardiac arrest, ${ }^{6}$ or 72 hours after complete rewarming if the patient undergoes TTM. ${ }^{9}$ The reasons are that no method is completely without risk of error, the reliability of several methods increase with time and the majority of patients with a good outcome will wake up before prognostication if it is delayed sufficiently. In the large TTM-trial, ${ }^{22}$ prognostication was scheduled for 72 hours after rewarming and eventually performed at a median of 117 hours postarrest. At this time point, 452 patients (48\%) had awoken, 139 (15\%) had died, and 313 (33\%) remained in a coma and had a formal neurologic evaluation. ${ }^{13}$ Thus, postponing the assessment will avoid unnecessary discussions on the level of care in the majority of patients. Early information on prognosis is still important to inform relatives who are usually in a state of shock and to inform important decisions on related interventions, such as cardiac reperfusion strategies ${ }^{11}$ or dialysis.

It is an unresolved controversy whether the use of TTM affects the reliability of the available tools for neuroprognostication. With the introduction of therapeutic hypothermia followed an increased use of analgosedation, a more active intensive care approach to the cardiac arrest victims in general and increased survival rates. It is therefore difficult to compare the results of prognostication studies performed before the introduction of temperature management with later studies using active temperature control. Hypothermia may delay the metabolism of sedative agents, ${ }^{51,52}$ but it is not clear whether this has any clinically relevant effects. Also, drug metabolism is delayed in critically ill patients in general. ${ }^{53}$ The TTM investigators found no difference in the reliability of routine $\mathrm{EEG},{ }^{54}$ serum $\mathrm{NSE}^{24}$ or the clinical examination ${ }^{12}$ between patients treated at 33 or $36^{\circ} \mathrm{C}$. Importantly, a lack of motor response or an extensor response to painful stimuli was not a reliable sign of a poor prognosis at 72 hours after arrest or with a further delay until 108 hours. Samaniego et al reported that hypothermia-treated patients 
received more sedation, and that corneal reflexes, motor response and, somewhat surprisingly, peak NSE were less reliable predictors of poor outcome in these patients compared with the noncooled controls. ${ }^{55}$

In previous guidelines from the Swedish Resuscitation Council, the expert group choose a cautionary approach and recommended to postpone all prognostication until 72 hours after rewarming for patients treated with hypothermia, similar to the TTM-trial. ${ }^{56}$ Lacking evidence for significant effects of temperature per se, such caution now seems less warranted leaving a room for the use of the most robust methods in the most severely injured patients already at 72 hours after the arrest as suggested in the algorithm outlined below.

\section{A Recommended Algorithm for Neuroprognostication}

The European Resuscitation Council (ERC) in collaboration with the European Society for Intensive Care Medicine (ESICM) issued recommendations on routines for neurological prognostication after cardiac arrest, ${ }^{57}$ including an algorithm based on available evidence ${ }^{58,59}$ and expert opinions (-Fig. 1). In this algorithm, the first assessment occurs at 72 hours postarrest. A prerequisite is that the patient is unconscious with extensor or no motor response, and that confounders such as sedation are excluded, which may, in fact, be hard to achieve completely. At 72 hours, only the bilateral lack of pupillary and corneal reflexes ${ }^{60}$ or the bilateral lack of somatosensory cortical N20 responses ${ }^{61}$ qualify for a statement of a very likely poor prognosis. If none of these criteria are fulfilled, the algorithm directs the clinician to a further 24 hours of observation without further analgosedation before reevaluation using multiple tools such as neuroimaging (computed tomography [CT] and magnetic resonance imaging [MRI]), ${ }^{62} \mathrm{EEG}^{63}{ }^{63}$ the biomarker $\mathrm{NSE},{ }^{64}$ and the clinical finding of status myoclonus; ${ }^{34,60}$ please refer to the appointed references for updated reviews on the methods. While there is strong evidence supporting the use of somatosensory-evoked potentials (SSEPs), pupillary and corneal reflexes, the evidence for the use of the other methods is less robust. ${ }^{58,59}$ Imaging, and EEG data have been difficult to standardize, limiting comparisons. As for routine EEG interpretation, a classification for the intensive care setting has been developed by the American Neurophysiological Society. ${ }^{65}$ Using this classification, highly malignant EEG patterns (-Fig. 2) predict the poor outcome with the substantial interrater agreement, ${ }^{66} 50 \%$ sensitivity, and $100 \%$ specificity. ${ }^{54}$ The use of these easily identified patterns was suggested in the updated guidelines from the Swedish Resuscitation Council 2017. ${ }^{67}$ A similar standard for neuroimaging is currently lacking. Differing cutoff levels for NSE have been suggested, partly due to lack of laboratory standards and variations between analytical, ${ }^{68}$ storage, and sampling methods. $^{69}$ Consequently, the ERC/ESICM-algorithm demands evidence from at least two of these additional methods to qualify a statement of a likely poor prognosis at 72 and 24 hours postarrest. For patients who fail to meet these criteria, the guideline recommendation is to continue intensive care, to consider confounding pharmacologic or

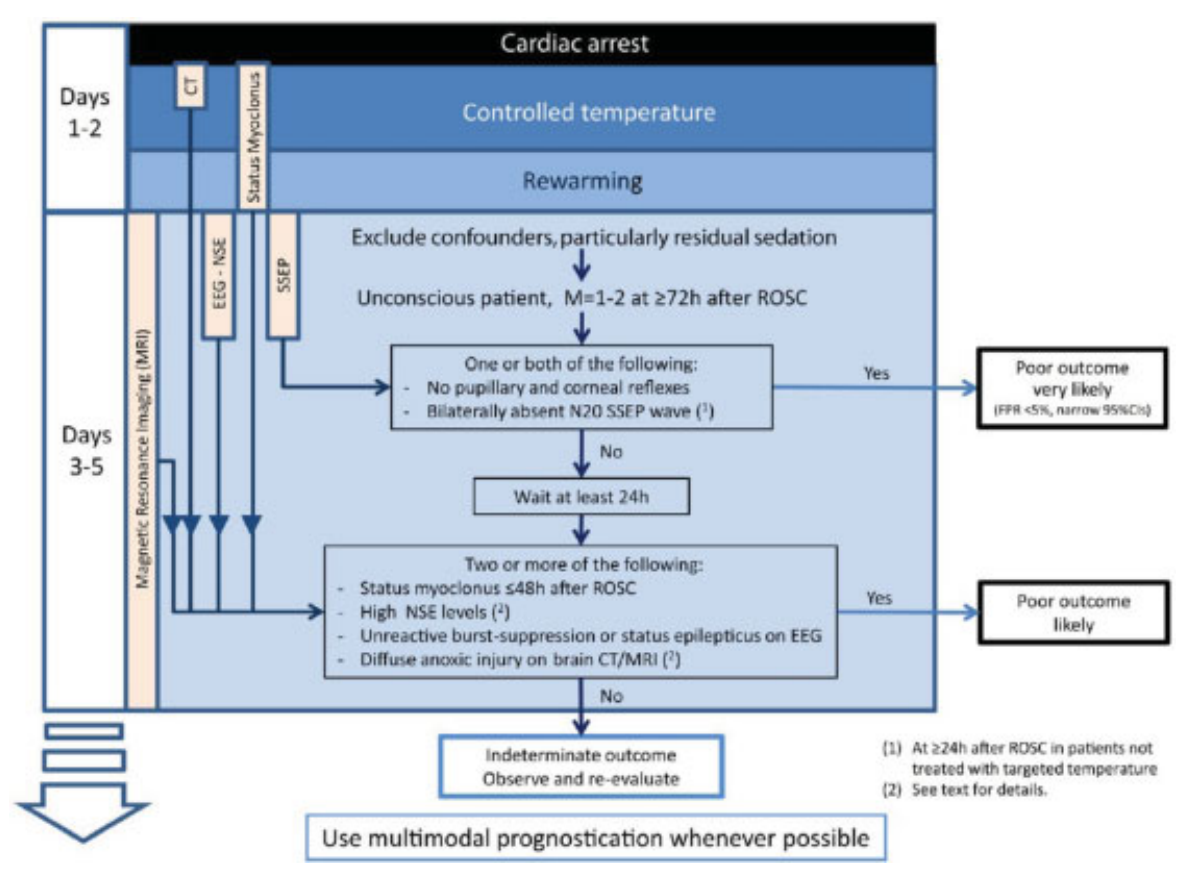

Fig. 1 Prognostication algorithm suggested by the European Resuscitation Council and the European Society for Intensive Care Medicine. A first statement on a poor prognosis can be made at $\geq 72$ hours after cardiac arrest if the patients have either bilateral absence of pupillary light reflexes and bilateral absence of corneal reflexes or bilateral absence of the somatosensory-evoked cortical N20 potentials. For patients not fulfilling these strict criteria, at least another 24 hours of observation without sedative medication is added before another evaluation using multiple tools. (Reproduced with permission from Sandroni et al. ${ }^{57}$ ) 

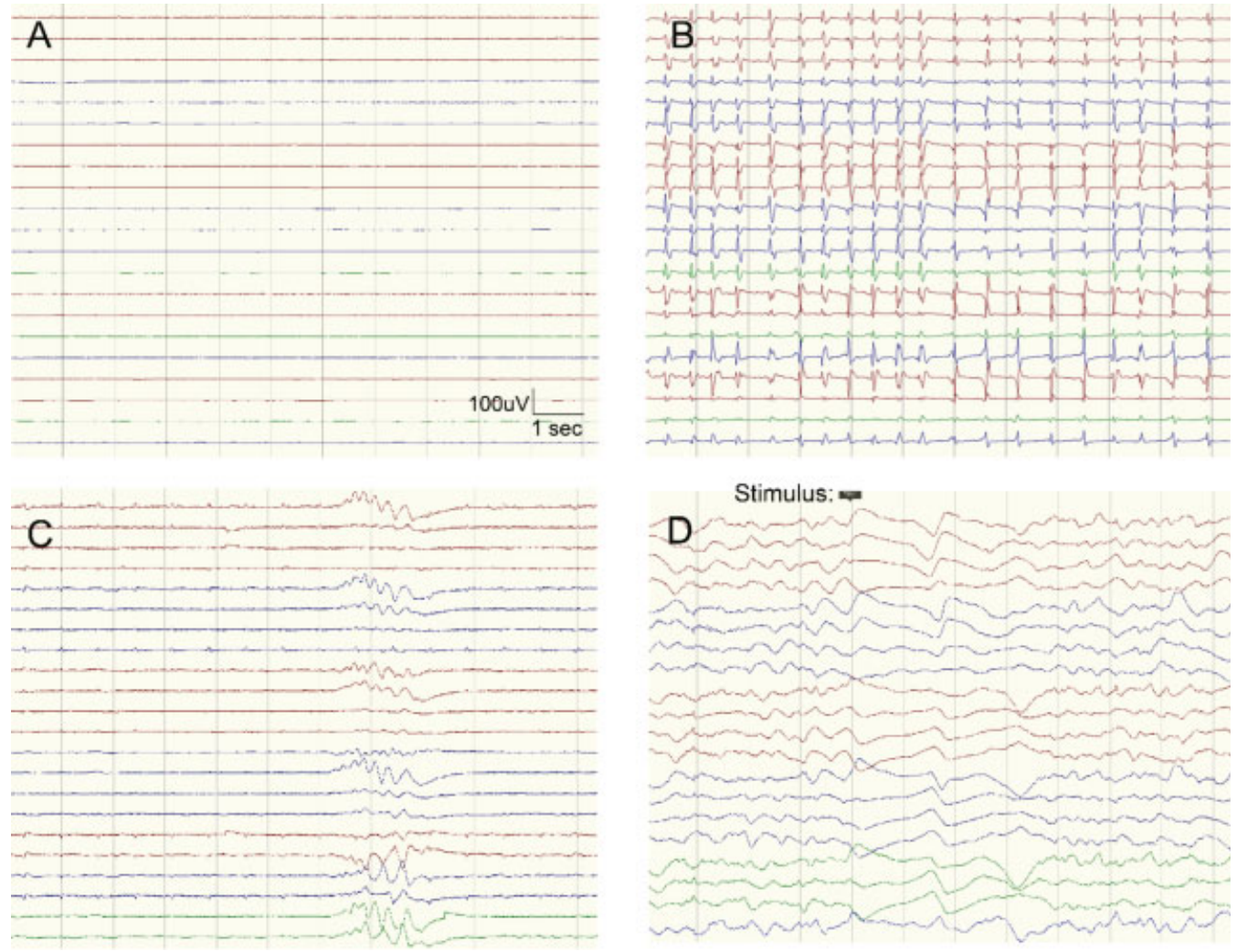

Fig. 2 Highly malignant $(A-C)$ and benign (D) patterns defined according to the standardized criteria developed by the American Neurophysiological Society. (A) Suppressed background $(<10 \mu \mathrm{V})$. (B) Suppressed background with superimposed continuous periodic discharges. (C) Burst suppression (periods of suppression constituting $>50 \%$ of the recording) with or without superimposed discharges. (D) Normal voltage $(>20 \mu \mathrm{V})$ background and preserved reactivity to stimuli. (Reproduced with permission from Westhall et al. ${ }^{54}$ )

metabolic factors, and to repeat examinations, such as EEG and MRI to gain more information. Although later awakening is a possibility in selected cases and this must not be forgotten, the vast majority of patients will awaken within 10 days after arrest. ${ }^{30}$

As a general rule, prognostication before 72 hours should be avoided, as it could lead to the premature withdrawal of intensive care on false premises. ${ }^{1}$ In a recent study from the United States, WLST before 72 hours for neurological reasons occurred in one-third of all patients dying in hospital after an OHCA. ${ }^{70}$ The authors extrapolated that premature WLST may cause the death of 1,500 American cardiac arrest patients yearly.

\section{A Practical Approach to Prognostication}

At our institution, a local protocol ( - Fig. 3 ) has been developed based on the ERC/ESICM algorithm. We perform a CT scan on all cardiac arrest patients without an obvious cardiac cause. If trauma is suspected, CT of the cervical spine is added and sometimes leads to the unexpected finding of a high cervical fracture causing tetraplegia. After admission to the ICU, all

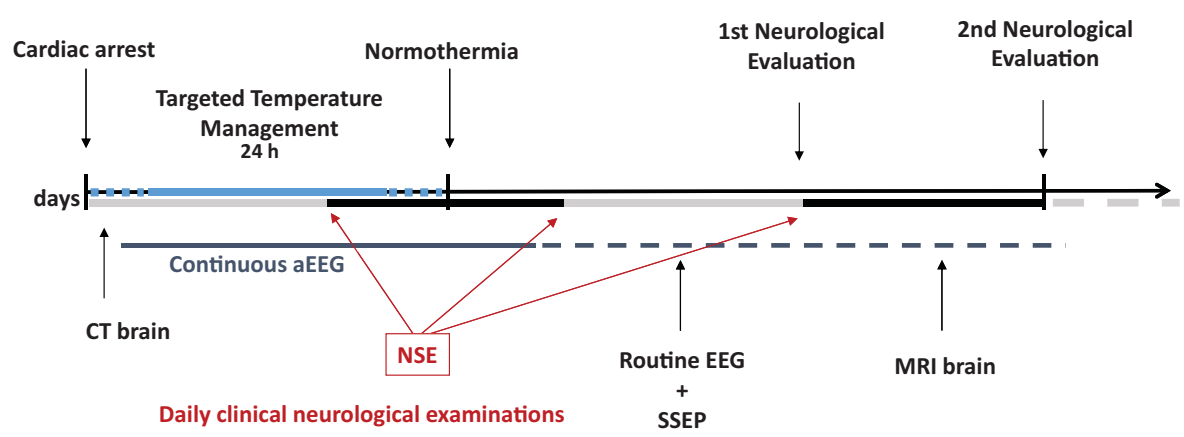

Fig. 3 Schematic drawing of the local protocol for neurological prognostication at the Skane University Hospital in Lund. All patients are monitored by continuous electrocardiogram (EEG) which is discontinued upon awakening. Serum neuron-specific enolase is sampled at 24,48 , and 72 hours. For patients who do not awaken upon weaning of sedation, routine EEG and somatosensory-evoked potential is performed at 48 to 72 hours and an magnetic resonance imaging of the brain may be added if the prognosis remain uncertain. 
patients are monitored by continuous simplified EEG which is administered by the ICU nurse. ${ }^{40}$ Also, NSE is measured at 24 , 48 , and 72 hours. For patients who wake up after weaning of sedation, no additional examinations are performed, and the EEG is not analyzed by a clinical neurophysiologist to save costs. If the patient remains comatose 48 to 72 hours after arrest, a routine EEG and SSEP are performed and an interpretation of the entire EEG monitoring period is performed by a clinical neurophysiologist. A neurologist will perform a clinical examination after 72 hours and conclude on the prognosis using the results from all investigations. If the evidence is still inconclusive, MRI of the brain will usually be the next step. We will only consider WLST at 72 hours if the SSEP-N20 responses are bilaterally absent or the pupillary and corneal reflexes are bilaterally absent; for all other patients, such decisions will wait at least another 24 hours. Already at 72 hours, however, a decision not to escalate care may be reasonable if there is clear evidence of a poor prognosis, such as generalized swelling on $\mathrm{CT}^{71}$ or a highly malignant EEG pattern. ${ }^{54}$ It is worth considering that the group of patients who remain in coma at the time point of prognostication as a group have a poor prognosis, and that an important task is to identify those with a potential for recovery with prolonged intensive care. In the TTM-trial, $85 \%$ of the prognosticated patients were either dead or suffered a severe neurological disability at 6 months follow-up. A recommendation of "donot-escalate" delayed death by a few days, but only 2/55 patients with such recommendation ultimately achieved a good outcome. Among patients with a recommendation to "continue care," 44/117(37\%) had a good outcome. ${ }^{13}$

\section{Withdrawal of Life-Sustaining Therapy}

As alluded to earlier, WLST is the most common direct cause of death among intensive care treated cardiac arrest victims. However, a decision to withdraw life-sustaining therapy is complex, and the neurological prognosis should be regarded as one important piece of information among others. A decision to withhold or withdraw intensive care may be justified for ethical reasons in patients without signs of severe brain injury, and continued care may also be justified when the evidence points toward a likely poor neurological prognosis. Traditions, legislation, and religious beliefs vary between countries and affect the practice of WLST and, as a consequence, the proportion of patients surviving with severe neurological disability. It is important to allow the patients' relatives sufficient time to prepare themselves, and a discussion on WLST should never come as a surprise to them. In most cases, early information from EEG monitoring, clinical examination and sometimes an early CT scan will have provided enough information for preliminary discussions with the relatives without depriving them of all hope.

\section{Long-Term Outcome among Cardiac Arrest Survivors}

In countries where neurological prognostication is translated into decisions on level-of-intensive care, survival with a severe neurological disability is relatively rare. The American Cardiac Arrest Registry to Enhance Survival reported that while survival from OHCA increased, significant trends showed decreasing fractions of patients discharged with moderate or severe neurological disability between 2007 and 2012. ${ }^{72}$ According to the Swedish Cardiac Arrest registry, only 6\% of survivors from OHCA during 2008 to 2011 had severe disability 30 days after arrest despite more than doubled survival rates during the preceding two decades. ${ }^{73}$ Large registries may be biased due underreporting from patients with severe disability less likely to participate in a follow-up. Also, assessing functional outcome at hospital discharge may lead to overly optimistic conclusions, since limitations in daily activities are not yet apparent. As a contrast to the reported registry data, the fraction of patients with severe disability in the TTM-trial 6 months after arrest was $9 \% .^{22}$

In countries where WLST is not practiced, outcome after cardiac arrest appears to be significantly different, with much higher rates of severely disabled patients. In a Korean single-center study 26/65 (40\%) surviving patients had a severe disability at 6 months, 19 (29\%) of whom were in a vegetative state. ${ }^{74}$ In a report from Israel, $27 \%$ of the survivors were on mechanical support at discharge from hospital, and most of these patients died during the study period. ${ }^{75}$

For patients in coma several weeks after the cardiac arrest, provision of intense rehabilitation was evaluated in a study from Germany. Despite 4 months of rehabilitation, only $7 / 113$ patients (6\%) eventually achieved a good outcome. ${ }^{76}$

\section{Assessment of Outcome}

Neurological function among cardiac arrest survivors in large cohorts or registries was usually estimated by assessors using crude outcome scales. The Cerebral Performance Categories scale (CPC, - Table 1.) was a modification of the Glasgow Outcome Scale (GOS) for traumatic brain injury, introduced by the Pittsburgh group in the first Brain Resuscitation Clinical Trial (BRCT) as a means to evaluate brain injury more specifically. ${ }^{77}$ The BRCT investigators used the CPC scale in combination with Overall Performance Categories (OPC) to capture also general disability of noncerebral cause. The CPC/OPC categories were recommended by the Utstein consensus conference ${ }^{78}$ and had become the standard instrument for assessment of functional outcome after cardiac arrest, although the OPC part has gradually fallen out of use. The CPC categories were usually dichotomized as a good outcome (CPC 1-2) and poor outcome (CPC 3-5), which may seem logical as the discriminator will be the dependence on help from others for daily activities. This dichotomization may be less obvious when developing methods for neuroprognostication, as evidence for a poor outcome will be used to support decisions to withdraw intensive care, and CPC 3 may not be incompatible with meaningful life. Earlier studies on neuroprognostication commonly drew the line between CPC 3 and CPC $4,{ }^{59}$ whereas studies performed in the TTM-era with few exceptions use the CPC 1-2/CPC 3-5 dichotomization. ${ }^{58}$ From a statistical standpoint, it is 
Table 1 Comparison between the modified Rankin Scale and the Cerebral Performance Categories scale

\begin{tabular}{|c|c|}
\hline Modified Rankin Scale & Cerebral Performance Category \\
\hline 0 . No symptoms at all & $\begin{array}{l}\text { 1. Good recovery: Conscious, alert, able to work, might have } \\
\text { mild neurologic or psychological deficit }\end{array}$ \\
\hline $\begin{array}{l}\text { 1. No significant disability despite symptoms; able to carry } \\
\text { out all usual duties and activities }\end{array}$ & $\begin{array}{l}\text { 2. Moderate disability: Conscious, sufficient cerebral func- } \\
\text { tion for independent activities of daily life. Able to work in } \\
\text { sheltered environment }\end{array}$ \\
\hline $\begin{array}{l}\text { 2. Slight disability; unable to carry out all previous activities, } \\
\text { but able to look after own affairs without assistance }\end{array}$ & $\begin{array}{l}\text { 3. Severe disability: Conscious, dependent on others for } \\
\text { daily support because of impaired brain function. Ranges } \\
\text { from ambulatory state to severe dementia or paralysis }\end{array}$ \\
\hline $\begin{array}{l}\text { 3. Moderate disability; requiring some help, but able to walk } \\
\text { without assistance }\end{array}$ & $\begin{array}{l}\text { 4. Coma or vegetative state: Any degree of coma without the } \\
\text { presence of all brain death criteria }\end{array}$ \\
\hline $\begin{array}{l}\text { 4. Moderately severe disability; unable to walk without } \\
\text { assistance and unable to attend to own bodily needs } \\
\text { without assistance }\end{array}$ & 5. Death: Apnea, electroencephalographic silence, etc. \\
\hline \multicolumn{2}{|l|}{$\begin{array}{l}\text { 5. Severe disability; bedridden, incontinent, requiring con- } \\
\text { stant nursing care and attention }\end{array}$} \\
\hline 6. Death: Apnea, electroencephalographic silence, etc. & \\
\hline
\end{tabular}

Source: Reproduced with permission from Elmer and Callaway. ${ }^{93}$

Note: The modified Rankin Scale (mRS) has a higher resolution in the upper end of the scale since mRS categories 1 to 3 roughly corresponds to Cerebral Performance Category 1 . The mRS has more focus on physical function, the ability to walk being the discriminator between mRS 3 and 4 .

probably less important that CPC 3 is included in the expected poor outcome scenario since most patients with poor outcome belong to the CPC 5 group (dead). It may still be a reason for some consideration when discussing WLST with relatives.

An attractive alternative to the CPC scale is the modified Rankin Scale (mRS) which was developed and validated for stroke $^{79,80}$ but has become gradually more popular also in cardiac arrest studies. Advantages are mainly a much better differentiation in the good outcome section ( - Table 1 ), but an obvious disadvantage is the focus on physical function (walking) which is more seldom affected among the severely disabled cardiac arrest patients (CPC 3 ).

Whereas the CPC scale has remained largely unchanged since its origin, the GOS has been modified to better capture outcome after traumatic brain injury. The categories have been extended to increase differentiation and structured interviews for better interrater reliability. ${ }^{81}$ Whether the extended GOS scale is superior to the mRS or even the CPC scale is still a matter of debate, but the Core Outcome Set after Cardiac Arrest initiative will provide guidance on how to choose wisely. ${ }^{82}$

\section{Cognitive Disability}

Whereas the crude neurological outcome is generally good among the vast majority of cardiac arrest survivors, studies using neuropsychological tests report that as many as half of survivors have problems, mainly regarding memory, executive function, and attention/processing speed. ${ }^{83}$ Such problems may not only be due to the cardiac arrest since control patients with myocardial infarction and a similar risk factor profile had cognitive impairment with almost equal frequency in a large TTM substudy. ${ }^{25}$ Cognitive impairment due to the cardiovascular burden is an important confounder when assessing cognition after cardiac arrest, and the risk of further deterioration should not be underestimated. In a small Swedish study with 17 years follow-up, most patients had died from cardiovascular causes, and 7/8 survivors had below normal scores on a cognitive screening test. ${ }^{84}$ The cardiovascular burden is known as a major determinant of age-related cognitive decline in general, ${ }^{85}$ and the cardiac arrest population is no exception, most having a cardiac atherosclerotic cause of their arrest and multiple cardiovascular risk factors.

\section{Other Related Outcomes}

Health-related quality of life is reported as good among the cardiac arrest survivors, ${ }^{23,86,87}$ but cognitive impairment may lead to reduced quality of life $\mathrm{e}^{88}$ and increases the strain on caregivers further. ${ }^{89}$ Cognitive impairment is also related to a reduced participation in societal activities (Gisela Lilja, OT, PhD, personal communication). Psychological distress was found to be another important factor for life quality after cardiac arrest, but the levels of anxiety and depression were not significantly elevated among the cardiac arrest survivors compared with myocardial infarction patients in the TTM substudy. ${ }^{90}$

\section{Follow-Up}

Since most patients who survive an OHCA have an underlying cardiac disorder and as many as half have cognitive problems, follow-up programs need to take cardiologic and neurologic aspects into account. In the follow-up program at our institution, cognitive screening and further referral to brain-oriented rehabilitation have been the standard for 
several years. ${ }^{91}$ Goossens and her coworkers in the Netherlands have developed an interesting collaboration around cardiac and brain injury at the Rijnland rehabilitation center, which may serve as an excellent example of modern cardiac arrest rehabilitation. ${ }^{92}$

\section{Conclusions}

Once circulation has stabilized, hypoxic-ischemic brain injury is the major cause of morbidity and mortality for the cardiac arrest patient in the ICU. Besides general respiratory and metabolic optimization, investigations to evaluate the extent and development of brain injury are important parts of modern post-cardiac arrest care. To avoid premature withdrawal of intensive care, local protocols for neuroprognostication based on national and international consensus documents should be available. The practice of modern neuroprognostication may help optimize outcome and avoid unnecessary suffering for patients and relatives.

When designing follow-up programs for cardiac arrest survivors, cardiac issues, and cognitive disability are important elements. Interventions against preventable risk factors are likely to have effects on both.

\section{References}

1 Cronberg T, Kuiper M. Withdrawal of life-sustaining therapy after cardiac arrest. Semin Neurol 2017;37(01):81-87

2 Berdowski J, Berg RA, Tijssen JG, Koster RW. Global incidences of out-of-hospital cardiac arrest and survival rates: Systematic review of 67 prospective studies. Resuscitation 2010;81(11): 1479-1487

3 Mortality GBD; GBD 2015 Mortality and Causes of Death Collaborators. Global, regional, and national life expectancy, all-cause mortality, and cause-specific mortality for 249 causes of death, 1980-2015: a systematic analysis for the Global Burden of Disease Study 2015. Lancet 2016;388(10053):1459-1544

4 Daya MR, Schmicker RH, Zive DM, et al; Resuscitation Outcomes Consortium Investigators. Out-of-hospital cardiac arrest survival improving over time: Results from the Resuscitation Outcomes Consortium (ROC). Resuscitation 2015;91:108-115

5 Wissenberg M, Lippert FK, Folke F, et al. Association of national initiatives to improve cardiac arrest management with rates of bystander intervention and patient survival after out-of-hospital cardiac arrest. JAMA 2013;310(13):1377-1384

6 Nolan JP, Soar J, Cariou A, et al; European Resuscitation Council; European Society of Intensive Care Medicine. European Resuscitation Council and European Society of Intensive Care Medicine 2015 guidelines for post-resuscitation care. Intensive Care Med 2015;41(12):2039-2056

7 Hasselqvist-Ax I, Riva G, Herlitz J, et al. Early cardiopulmonary resuscitation in out-of-hospital cardiac arrest. N Engl J Med 2015; 372(24):2307-2315

8 Deakin CD, Fothergill R, Moore F, Watson L, Whitbread M. Level of consciousness on admission to a heart attack centre is a predictor of survival from out-of-hospital cardiac arrest. Resuscitation 2014;85(07):905-909

9 Callaway CW, Donnino MW, Fink EL, et al. Part 8: post-cardiac arrest care: 2015 American Heart Association guidelines update for cardiopulmonary resuscitation and emergency cardiovascular care. Circulation 2015;132(18, Suppl 2):S465-S482
10 Geocadin RG, Wijdicks E, Armstrong MJ, et al. Practice guideline summary: Reducing brain injury following cardiopulmonary resuscitation: Report of the Guideline Development, Dissemination, and Implementation Subcommittee of the American Academy of Neurology. Neurology 2017;88(22):2141-2149

11 Bougouin W, Cariou A. Cardiac issues in cardiac arrest. Semin Neurol 2017;37(01):13-18

12 Dragancea I, Rundgren M, Englund E, Friberg H, Cronberg T. The influence of induced hypothermia and delayed prognostication on the mode of death after cardiac arrest. Resuscitation 2013;84 (03):337-342

13 Dragancea I, Wise MP, Al-Subaie N, et al; TTM trial investigators. Protocol-driven neurological prognostication and withdrawal of life-sustaining therapy after cardiac arrest and targeted temperature management. Resuscitation 2017;117:50-57

14 Laver S, Farrow C, Turner D, Nolan J. Mode of death after admission to an intensive care unit following cardiac arrest. Intensive Care Med 2004;30(11):2126-2128

15 Lemiale V, Dumas F, Mongardon N, et al. Intensive care unit mortality after cardiac arrest: the relative contribution of shock and brain injury in a large cohort. Intensive Care Med 2013;39 (11):1972-1980

16 Pana R, Hornby L, Shemie SD, Dhanani S, Teitelbaum J. Time to loss of brain function and activity during circulatory arrest. J Crit Care 2016;34:77-83

17 Busl KM, Greer DM. Hypoxic-ischemic brain injury: pathophysiology, neuropathology and mechanisms. NeuroRehabilitation 2010;26(01):5-13

18 Björklund E, Lindberg E, Rundgren M, Cronberg T, Friberg H, Englund E. Ischaemic brain damage after cardiac arrest and induced hypothermia-a systematic description of selective eosinophilic neuronal death. A neuropathologic study of 23 patients. Resuscitation 2014;85(04):527-532

19 Cariou A, Payen JF, Asehnoune K, et al; Société de Réanimation de Langue Française (SRLF) and the Société Française d'Anesthésie et de Réanimation (SFAR) In conjunction with the Association de Neuro Anesthésie Réanimation de Langue Française (ANARLF), the Groupe Francophone de Réanimation et Urgences Pédiatriques (GFRUP), the Société Française de Médecine d'Urgence (SFMU), and the Société Française Neuro-Vasculaire (SFNV). Targeted temperature management in the ICU: guidelines from a French expert panel. Ann Intensive Care 2017;7(01):70

20 Bernard SA, Gray TW, Buist MD, et al. Treatment of comatose survivors of out-of-hospital cardiac arrest with induced hypothermia. N Engl J Med 2002;346(08):557-563

21 Hypothermia after Cardiac Arrest Study Group. Mild therapeutic hypothermia to improve the neurologic outcome after cardiac arrest. N Engl J Med 2002;346(08):549-556

22 Nielsen N, Wetterslev J, Cronberg T, et al; TTM Trial Investigators. Targeted temperature management at $33^{\circ} \mathrm{C}$ versus $36^{\circ} \mathrm{C}$ after cardiac arrest. N Engl J Med 2013;369(23):2197-2206

23 Cronberg T, Lilja G, Horn J, et al; TTM Trial Investigators. neurologic function and health-related quality of life in patients following targeted temperature management at $33^{\circ} \mathrm{C}$ vs $36^{\circ} \mathrm{C}$ after out-of-hospital cardiac arrest: a randomized clinical trial. JAMA Neurol 2015;72(06):634-641

24 Stammet P, Collignon O, Hassager C, et al; TTM-Trial Investigators. Neuron- specific enolase as a predictor of death or poor neurological outcome after out-of-hospital cardiac arrest and targeted temperature management at $33^{\circ} \mathrm{C}$ and $36^{\circ} \mathrm{C}$. J Am Coll Cardiol 2015;65(19):2104-2114

25 Lilja G, Nielsen N, Friberg H, et al. Cognitive function in survivors of out-of-hospital cardiac arrest after target temperature management at $33^{\circ} \mathrm{C}$ versus $36^{\circ} \mathrm{C}$. Circulation 2015;131(15): 1340-1349

26 Kirkegaard H, Søreide E, de Haas I, et al. Targeted temperature management for 48 vs 24 hours and neurologic outcome after 
out-of-hospital cardiac arrest: a randomized clinical trial. JAMA 2017;318(04):341-350

27 Zeiner A, Holzer M, Sterz F, et al. Hyperthermia after cardiac arrest is associated with an unfavorable neurologic outcome. Arch Intern Med 2001;161(16):2007-2012

28 Schefold JC, Storm C, Krüger A, Ploner CJ, Hasper D. The Glasgow Coma Score is a predictor of good outcome in cardiac arrest patients treated with therapeutic hypothermia. Resuscitation 2009;80(06):658-661

29 Grossestreuer AV, Abella BS, Leary M, et al. Time to awakening and neurologic outcome in therapeutic hypothermia-treated cardiac arrest patients. Resuscitation 2013;84(12):1741-1746

30 Gold B, Puertas L, Davis SP, et al. Awakening after cardiac arrest and post resuscitation hypothermia: are we pulling the plug too early? Resuscitation 2014;85(02):211-214

31 Knight WA, Hart KW, Adeoye OM, et al. The incidence of seizures in patients undergoing therapeutic hypothermia after resuscitation from cardiac arrest. Epilepsy Res 2013;106(03):396-402

32 Lybeck A, Friberg H, Aneman A, et al; TTM-trial Investigators. Prognostic significance of clinical seizures after cardiac arrest and target temperature management. Resuscitation 2017;114:146-151

33 Thömke F, Weilemann SL. Poor prognosis despite successful treatment of postanoxic generalized myoclonus. Neurology 2010;74(17):1392-1394

34 Reynolds AS, Claassen J. Treatment of seizures and postanoxic status epilepticus. Semin Neurol 2017;37(01):33-39

35 Seder DB, Sunde K, Rubertsson S, et al; International Cardiac Arrest Registry. Neurologic outcomes and postresuscitation care of patients with myoclonus following cardiac arrest. Crit Care Med 2015;43(05):965-972

36 Lucas JM, Cocchi MN, Salciccioli J, et al. Neurologic recovery after therapeutic hypothermia in patients with post-cardiac arrest myoclonus. Resuscitation 2012;83(02):265-269

37 Greer DM. Unexpected good recovery in a comatose post-cardiac arrest patient with poor prognostic features. Resuscitation 2013; 84(06):e81-e82

38 Elmer J, Rittenberger JC, Faro J, et al; Pittsburgh Post-Cardiac Arrest Service. Clinically distinct electroencephalographic phenotypes of early myoclonus after cardiac arrest. Ann Neurol 2016; 80(02):175-184

39 Werhahn KJ, Brown P, Thompson PD, Marsden CD. The clinical features and prognosis of chronic posthypoxic myoclonus. Mov Disord 1997;12(02):216-220

40 Friberg H, Westhall E, Rosén I, Rundgren M, Nielsen N, Cronberg T. Clinical review: Continuous and simplified electroencephalography to monitor brain recovery after cardiac arrest. Crit Care 2013; 17(04):233

41 Dragancea I, Backman S, Westhall E, Rundgren M, Friberg H, Cronberg T. Outcome following postanoxic status epilepticus in patients with targeted temperature management after cardiac arrest. Epilepsy Behav 2015;49:173-177

42 Legriel S, Hilly-Ginoux J, Resche-Rigon M, et al. Prognostic value of electrographic postanoxic status epilepticus in comatose cardiacarrest survivors in the therapeutic hypothermia era. Resuscitation 2013;84(03):343-350

43 Rossetti AO, Logroscino G, Liaudet L, et al. Status epilepticus: an independent outcome predictor after cerebral anoxia. Neurology 2007;69(03):255-260

44 Backman S, Westhall E, Dragancea I, et al. Electroencephalographic characteristics of status epilepticus after cardiac arrest. Clin Neurophysiol 2017;128(04):681-688

45 Westhall E, Rundgren M, Lilja G, Friberg H, Cronberg T. Postanoxic status epilepticus can be identified and treatment guided successfully by continuous electroencephalography. Ther Hypothermia Temp Manag 2013;3(02):84-87

46 Ruijter BJ, van Putten MJ, Hofmeijer J. Generalized epileptiform discharges in postanoxic encephalopathy: Quantitative charac- terization in relation to outcome. Epilepsia 2015;56(11): 1845-1854

47 Ruijter BJ, van Putten MJ, Horn J, et al; TELSTAR study group. Treatment of electroencephalographic status epilepticus after cardiopulmonary resuscitation (TELSTAR): study protocol for a randomized controlled trial. Trials 2014;15:433

48 Greer DM, Rosenthal ES, Wu O. Neuroprognostication of hypoxicischaemic coma in the therapeutic hypothermia era. Nat Rev Neurol 2014;10(04):190-203

49 Rossetti AO, Rabinstein AA, Oddo M. Neurological prognostication of outcome in patients in coma after cardiac arrest. Lancet Neurol 2016;15(06):597-609

50 Friberg H, Rundgren M, Westhall E, Nielsen N, Cronberg T. Continuous evaluation of neurological prognosis after cardiac arrest. Acta Anaesthesiol Scand 2013;57(01):6-15

51 Tortorici MA, Kochanek PM, Poloyac SM. Effects of hypothermia on drug disposition, metabolism, and response: A focus of hypothermia-mediated alterations on the cytochrome P450 enzyme system. Crit Care Med 2007;35(09):2196-2204

52 Hostler D, Zhou J, Tortorici MA, et al. Mild hypothermia alters midazolam pharmacokinetics in normal healthy volunteers. Drug Metab Dispos 2010;38(05):781-788

53 Varghese JM, Roberts JA, Lipman J. Pharmacokinetics and pharmacodynamics in critically ill patients. Curr Opin Anaesthesiol 2010;23(04):472-478

54 Westhall E, Rossetti AO, van Rootselaar AF, et al; TTM-trial investigators. Standardized EEG interpretation accurately predicts prognosis after cardiac arrest. Neurology 2016;86(16):1482-1490

55 Samaniego EA, Mlynash M, Caulfield AF, Eyngorn I, Wijman CA. Sedation confounds outcome prediction in cardiac arrest survivors treated with hypothermia. Neurocrit Care 2011;15(01): 113-119

56 Cronberg T, Brizzi M, Liedholm LJ, et al. Neurological prognostication after cardiac arrest-recommendations from the Swedish Resuscitation Council. Resuscitation 2013;84(07):867-872

57 Sandroni C, Cariou A, Cavallaro F, et al. Prognostication in comatose survivors of cardiac arrest: an advisory statement from the European Resuscitation Council and the European Society of Intensive Care Medicine. Resuscitation 2014;85(12):1779-1789

58 Sandroni C, Cavallaro F, Callaway CW, et al. Predictors of poor neurological outcome in adult comatose survivors of cardiac arrest: a systematic review and meta-analysis. Part 2: Patients treated with therapeutic hypothermia. Resuscitation 2013;84 (10):1324-1338

59 Sandroni C, Cavallaro F, Callaway CW, et al. Predictors of poor neurological outcome in adult comatose survivors of cardiac arrest: a systematic review and meta-analysis. Part 1: patients not treated with therapeutic hypothermia. Resuscitation 2013;84 (10):1310-1323

60 Sandroni C, D'Arrigo S. Neurologic prognostication: neurologic examination and current guidelines. Semin Neurol 2017;37(01): 40-47

61 Horn J, Tjepkema-Cloostermans MC. Somatosensory evoked potentials in patients with hypoxic-ischemic brain injury. Semin Neurol 2017;37(01):60-65

62 Greer DM, Wu O. Neuroimaging in cardiac arrest prognostication. Semin Neurol 2017;37(01):66-74

63 Westhall E. Electroencephalography as a prognostic tool after cardiac arrest. Semin Neurol 2017;37(01):48-59

64 Stammet P. Blood biomarkers of hypoxic-ischemic brain injury after cardiac arrest. Semin Neurol 2017;37(01):75-80

65 Hirsch LJ, LaRoche SM, Gaspard N, et al. American Clinical Neurophysiology Society's standardized critical care EEG terminology: 2012 version. J Clin Neurophysiol 2013;30(01):1-27

66 Westhall E, Rosén I, Rossetti AO, et al. Interrater variability of EEG interpretation in comatose cardiac arrest patients. Clin Neurophysiol 2015;126(12):2397-2404 
67 Rylander C, Friberg H, Larsson EM, Liedholm LJ, Rubertsson S, Cronberg T. Bedömning av neurologisk prognos efter hjärtstopp [article in Swedish; abstract in English]. Lakartidningen 2017;114:EIUH

68 Stern P, Bartos V, Uhrova J, et al. Performance characteristics of seven neuron-specific enolase assays. Tumour Biol 2007;28(02): 84-92

69 Rundgren M, Cronberg T, Friberg H, Isaksson A. Serum neuron specific enolase-impact of storage and measuring method. BMC Res Notes 2014;7:726

70 Elmer J, Torres C, Aufderheide TP, et al; Resuscitation Outcomes Consortium. Association of early withdrawal of life-sustaining therapy for perceived neurological prognosis with mortality after cardiac arrest. Resuscitation 2016;102:127-135

71 Moseby-Knappe M, Pellis T, Dragancea I, et al; TTM-trial investigators. Head computed tomography for prognostication of poor outcome in comatose patients after cardiac arrest and targeted temperature management. Resuscitation 2017;119:89-94

72 Chan PS, McNally B, Tang F, Kellermann A; CARES Surveillance Group. Recent trends in survival from out-of-hospital cardiac arrest in the United States. Circulation 2014;130(21):1876-1882

73 Strömsöe A, Svensson L, Axelsson AB, et al. Improved outcome in Sweden after out-of-hospital cardiac arrest and possible association with improvements in every link in the chain of survival. Eur Heart J 2015;36(14):863-871

$74 \mathrm{Kim}$ YJ, Ahn S, Sohn CH, et al. Long-term neurological outcomes in patients after out-of-hospital cardiac arrest. Resuscitation 2016; 101:1-5

75 Pachys G, Kaufman N, Bdolah-Abram T, Kark JD, Einav S. Predictors of long-term survival after out-of-hospital cardiac arrest: the impact of activities of daily living and cerebral performance category scores. Resuscitation 2014;85(08):1052-1058

76 Howell K, Grill E, Klein AM, Straube A, Bender A. Rehabilitation outcome of anoxic-ischaemic encephalopathy survivors with prolonged disorders of consciousness. Resuscitation 2013;84 (10):1409-1415

77 Brain Resuscitation Clinical Trial I Study Group. A randomized clinical study of cardiopulmonary-cerebral resuscitation: design, methods, and patient characteristics. Am J Emerg Med 1986;4(01):72-86

78 Cummins RO, Chamberlain DA, Abramson NS, et al. Recommended guidelines for uniform reporting of data from out-ofhospital cardiac arrest: the Utstein Style. A statement for health professionals from a task force of the American Heart Association, the European Resuscitation Council, the Heart and Stroke Foundation of Canada, and the Australian Resuscitation Council. Circulation 1991;84(02):960-975
79 Tilley BC, Marler J, Geller NL, et al. Use of a global test for multiple outcomes in stroke trials with application to the National Institute of Neurological Disorders and Stroke t-PA Stroke Trial. Stroke 1996;27(11):2136-2142

80 van Swieten JC, Koudstaal PJ, Visser MC, Schouten HJ, van Gijn J. Interobserver agreement for the assessment of handicap in stroke patients. Stroke 1988;19(05):604-607

81 Wilson JT, Pettigrew LE, Teasdale GM. Structured interviews for the Glasgow Outcome Scale and the extended Glasgow Outcome Scale: guidelines for their use. J Neurotrauma 1998;15(08): 573-585

82 Whitehead L, Perkins GD, Clarey A, Haywood KL. A systematic review of the outcomes reported in cardiac arrest clinical trials: the need for a core outcome set. Resuscitation 2015;88: 150-157

83 Moulaert VR, Verbunt JA, van Heugten CM, Wade DT. Cognitive impairments in survivors of out-of-hospital cardiac arrest: a systematic review. Resuscitation 2009;80(03):297-305

84 Andersson AE, Rosén H, Sunnerhagen KS. Life after cardiac arrest: A very long term follow up. Resuscitation 2015;91:99-103

85 Qiu C, Fratiglioni L. A major role for cardiovascular burden in agerelated cognitive decline. Nat Rev Cardiol 2015;12(05):267-277

86 Elliott VJ, Rodgers DL, Brett SJ. Systematic review of quality of life and other patient-centred outcomes after cardiac arrest survival. Resuscitation 2011;82(03):247-256

87 Smith K, Andrew E, Lijovic M, Nehme Z, Bernard S. Quality of life and functional outcomes 12 months after out-of-hospital cardiac arrest. Circulation 2015;131(02):174-181

88 Moulaert VR, Wachelder EM, Verbunt JA, Wade DT, van Heugten CM. Determinants of quality of life in survivors of cardiac arrest. J Rehabil Med 2010;42(06):553-558

89 van Wijnen HG, Rasquin SM, van Heugten CM, Verbunt JA, Moulaert VR. The impact of cardiac arrest on the long-term wellbeing and caregiver burden of family caregivers: a prospective cohort study. Clin Rehabil 2017;31(09):1267-1275

90 Lilja G, Nilsson G, Nielsen N, et al. Anxiety and depression among out-of-hospital cardiac arrest survivors. Resuscitation 2015; 97:68-75

91 Lilja G. Follow-up of cardiac arrest survivors: why, how, and when? a practical approach. Semin Neurol 2017;37(01):88-93

92 Boyce LW, Goossens PH. Rehabilitation after cardiac arrest: integration of neurologic and cardiac rehabilitation. Semin Neurol 2017;37(01):94-102

93 Elmer J, Callaway CW. The brain after cardiac arrest. Semin Neurol 2017;37(01):19-24 